\title{
Historical perspectives of The American Association for Thoracic Surgery: James Lewis Cox (1942-)
}

\author{
Jennifer S. Lawton, MD, ${ }^{\mathrm{a}}$ and Thomas A. D'Amico, $\mathrm{MD}^{\mathrm{b}}$
}

James Lewis Cox, MD, was the 81st president of The American Association for Thoracic Surgery (AATS) from 2000 to 2001 (Figure 1). Although his contributions to thoracic surgery have been, and will continue to be, remarkable, he is best known for his extensive work investigating the mechanism responsible for atrial fibrillation and its successful surgical cure with the maze procedure. ${ }^{1} \mathrm{Dr}$ Cox has described this as his most important contribution to thoracic surgery (personal communication, February 23, 2013). His academic career epitomizes the importance of basic laboratory investigation of the pathophysiology of disease and successful translation to clinical patient benefit.

\section{EARLY CHOICES: BASEBALL VERSUS MEDICINE}

Dr Cox was born in Far Oaks, Arkansas, and grew up on a rice farm. He attended the University of Mississippi with a 3 -sport athletic scholarship in football, basketball, and baseball. He completed an application to medical school while undergoing rehabilitation after knee surgery. One day during the summer of 1963, at 20 years of age, he took a lunch break while working on the farm and made a very important decision. His mother presented him with an acceptance letter from the University of Tennessee School of Medicine, and his father told him that a scout for the Los Angeles Dodgers had telephoned that same day to offer him a salary and bonus to play shortstop for the Dodgers. Without hesitation, he chose medical school and graduated from the University of Tennessee School of Medicine with academic honors in 1967, with election to the Alpha Omega Alpha Honor Society.

During medical school, his interest in the study of cardiac arrhythmias began while working in the laboratories of $\mathrm{Dr}$ Leo G. Horan and Dr Nancy C. Flowers. During that time, he wrote the first report to describe the ischemic zones surrounding an acute myocardial infarction. ${ }^{2} \mathrm{He}$ continued to pursue this interest during his general surgery residency at Duke University, during which he worked in the laboratory of Dr John P. Boineau (Figure 2).

\footnotetext{
From the Division of Cardiothoracic Surgery, ${ }^{\mathrm{a}}$ Department of Surgery, Washington University School of Medicine, St Louis, Mo; and Duke University Medical Center, ${ }^{\mathrm{b}}$ Durham, NC.

Disclosures: Authors have nothing to disclose with regard to commercial support.

Received for publication Sept 12, 2013; accepted for publication Sept 13, 2013; available ahead of print Oct 28, 2013.

Address for reprints: Jennifer S. Lawton, MD, Department of Surgery, Washington University School of Medicine, 660 S Euclid Ave, Campus Box 8234, St Louis,

MO 63110 (E-mail: lawtonj@wustl.edu).

J Thorac Cardiovasc Surg 2015;149:1235-9

$0022-5223 / \$ 36.00$

Copyright (c) 2015 by The American Association for Thoracic Surgery

http://dx.doi.org/10.1016/j.jtcvs.2013.09.005
}

\section{EARLY PROMOTION TO U.S. ARMY MAJOR}

Dr Cox left his general surgery residency for 2 years (1970-1972) for active duty in the U.S. Army Medical Corps, serving as captain from 1970 to 1971 and as major from 1971 to 1972. He received a personal commendation from Brigadier General George S. Patton III (son of World War II hero General George Patton, Jr), for saving an injured soldier after an antitank weapon had exploded in Fort Knox in 1971. Being the junior surgeon, he was assigned to the "least wounded" of 3 men. To his surprise, the "least wounded" had the rocket from the weapon lodged in his liver. For his role in saving the men, Dr Cox was awarded field promotion to major, became an honorary tanker, and received the coveted "scrambled eggs" (gold leaves) on his hat, indicating his rank.

\section{THE BEGINNING OF AN ACADEMIC CAREER}

Subsequently, Dr Cox returned to the research laboratory for an additional year and then completed his residency in general and cardiothoracic surgery (including 1 year as a teaching scholar) at Duke University in 1978, followed by 5 years as a National Institutes of Health Scholar in Academic Surgery. In 1978, he joined the faculty at Duke University under Dr David C. Sabiston, Jr (the 65th President of the AATS) as an assistant professor of surgery and rapidly ascended the academic ranks. He was promoted to associate professor in 1983. After only 4 months as an associate professor at Duke University, he was recruited to Washington University in St. Louis to be professor and chief of cardiothoracic surgery at the age of 40 years. While at Washington University, he led a tremendously active research laboratory (maintaining National Institutes of Health funding for 27 years), investigating the surgical treatment of cardiac arrhythmias and training future leaders in cardiac surgery (Figures 3 and 4). On September 25, 1987, Dr Cox performed the first maze procedure. In 1990, he became the first Evarts A. Graham (the 10th President of the AATS)-endowed professor of surgery and the vice-chair of the department of surgery in 1993.

\section{THE IMPORTANCE OF LABORATORY RESEARCH AND THE MAZE PROCEDURE}

Dr Cox pioneered the Cox-maze procedure, which remains the reference standard for the surgical treatment of atrial fibrillation. His interest in electrophysiology began in medical school and continued during his general surgery residency. In 1968, he was part of the operative team (fourth assistant) that performed the first operation 


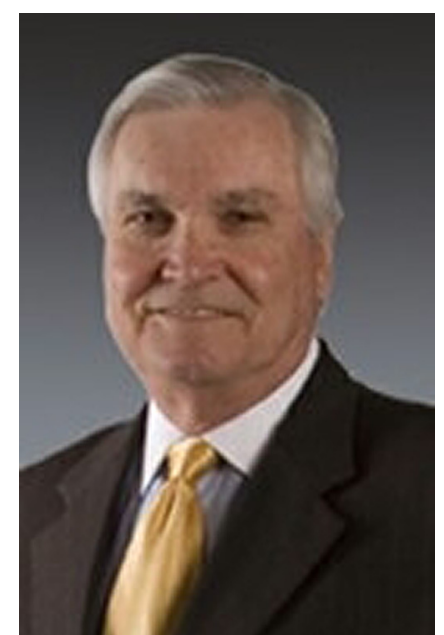

FIGURE 1. James Lewis Cox, MD. (Courtesy of Dr Thomas A. D'Amico.)

for Wolff-Parkinson-White syndrome at Duke. He began work on the treatment of atrioventricular nodal reentry as a faculty member at Duke and told Duke residents Drs Peter Smith and William Holman that "you always need to do something that is a little bit off the wall" (personal communication, February 23, 2013). They identified dogs with atrioventricular nodal pathways and began to investigate the necessary pathway ablation for the surgical cure of such patients. They attained the first clinical cure of atrioventricular nodal reentrant tachycardia using a discrete cryosurgical technique in August 1982.

Subsequent work developing the treatment of automatic atrial tachycardia using the left atrial isolation procedure "proved to be fundamental to the future success of the maze procedure." ${ }^{3}$ Dr Cox noted that "a seminal observation was that it was impossible to

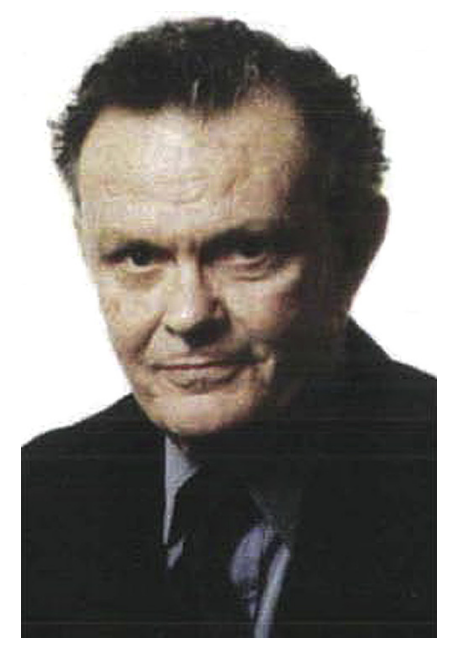

FIGURE 2. Photograph of John P. Boineau, MD. (Courtesy of Dr Schuessler.) isolate the left atrium from the right atrium electrically unless conduction through the walls of the coronary sinus was blocked. Further, it was shown that this coronary sinus conduction took place not in the atrial myocardial fibers surrounding the coronary sinus, but in the walls of the coronary sinus itself. This information later proved to be crucial in attaining complete conduction block through the 'left atrial isthmus' when performing the maze procedure" and that "in the presence of normal ventricles, the forward cardiac output is completely independent of the left atrial transport function as long as the right atrium remains in synchrony with the right ventricle." ${ }^{3}$ Similarly, work performed to disconnect the right ventricle from the remainder of the heart for the surgical treatment of arrhythmogenic right ventricular dysplasia ${ }^{3}$ brought insight into the conduction pathways responsible for pathologic features in the human heart. Important physiologic lessons learned by laboratory research and subsequent surgical implementation led to important, clinically useful, and beneficial treatments for patients. Dr Cox and his colleagues used the multiple lessons learned to describe the highly effective maze procedure for the treatment of atrial fibrillation that not only treats the patient's discomfort and anxiety from an irregularly irregular heartbeat, but also restores synchronous atrioventricular contraction and abolishes the risk of stroke from thromboembolism. ${ }^{3}$

In the development of the maze procedure, Dr Cox noted that atrial fibrillation was "characterized by the presence of multiple large, constantly shifting, macro-reentrant circuits in the atria" and that "we had to develop a procedure that made it impossible for the atrium to fibrillate at all." 4 Dr Cox combined the experimental maps of atrial fibrillation generated by Drs John Boineau and Richard Schuessler (Figure 5) with the atrial anatomy on a drawing of a rectangle (Figure 6). They determined that "atrial incisions placed no more than 5 to $6 \mathrm{~cm}$ apart should theoretically prevent the development of macro-reentrant circuits." $\mathrm{He}$ thus described the origin of the maze procedure as "creating a pattern of lesions in the atria that was essentially that of a simple maze."

The first and second surgical techniques (maze I and maze II) were modified to be easier to perform technically, creating the maze III procedure, which remains the technique of choice for atrial fibrillation (Figure 7). It is in this first understanding of pathophysiology at the basic level with the translation to clinical disease that Dr Cox made multiple seminal contributions to the treatment of cardiac arrhythmias.

\section{CONTINUED ACADEMIC SUCCESS AND HONORS}

In 1997, Dr Cox became the professor and chair of the Department of Thoracic and Cardiothoracic Surgery and 


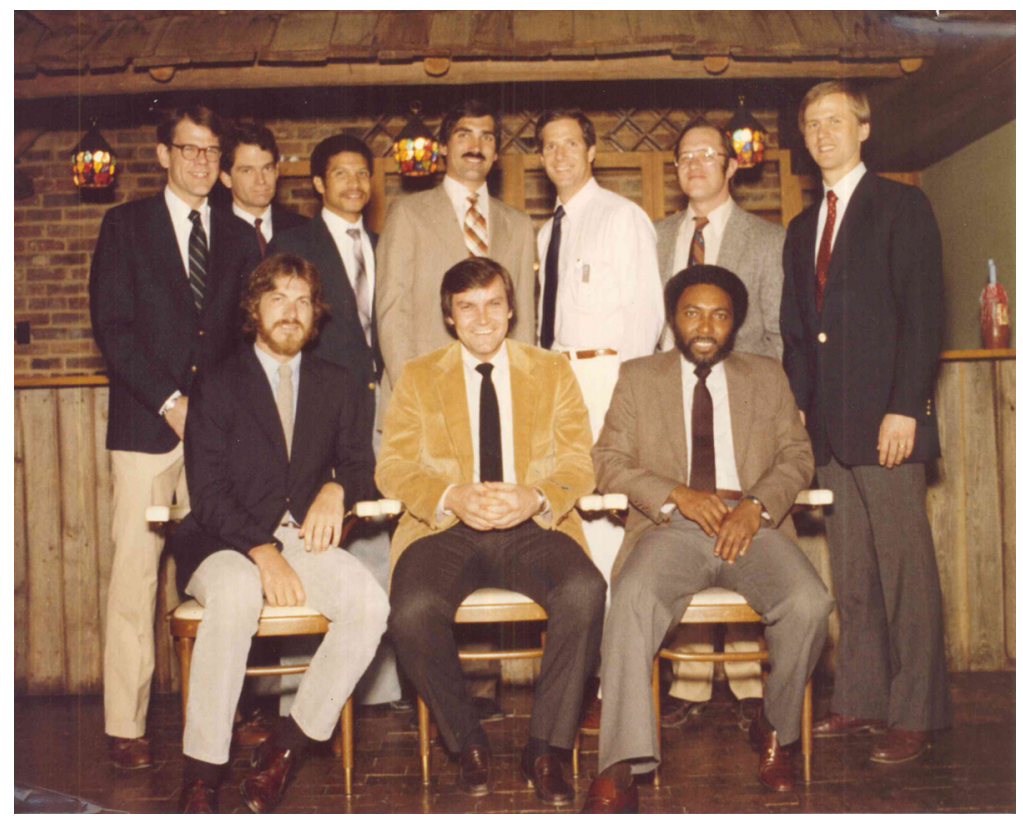

FIGURE 3. Dr Cox's surgical electrophysiology laboratory at Duke University (1978-1983). Standing left to right: T. Bruce Ferguson, MD, Gary K. Lofland, MD, James M. Douglas, MD, Ralph J. Damiano, Jr, MD, Ross M. Ungerleider, MD, Peter K. Smith, MD, and William L. Holman, MD; seated left to right: Barry H. Branham, computer engineer, James L. Cox, MD, and George Quick, chief laboratory technician. (Courtesy of Dr Ralph J. Damiano, Jr.)

director of the Georgetown Cardiovascular Institute at Georgetown University. In 2000, he was elected president of the World Heart Foundation and was named distinguished adjunct professor of surgery at the Ohio State University Medical Center. After having held multiple positions in the AATS, he was elected the Association's 81st president in 2000.

Dr Cox has numerous accomplishments and has made countless contributions to societies and boards. He has served as the chair of the Residency Review Committee for Thoracic Surgery, director of the American Board of Thoracic Surgery and the Board of Directors of the

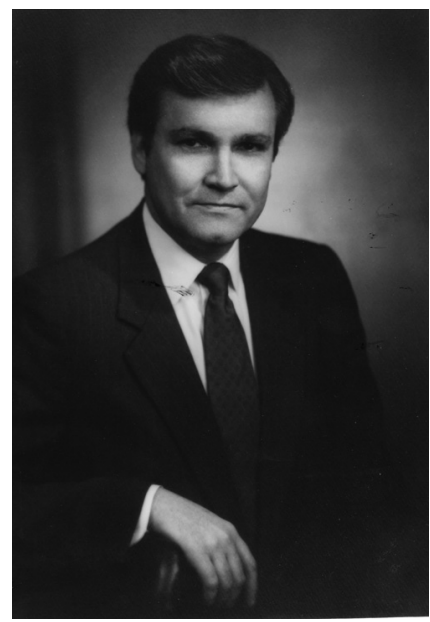

FIGURE 4. Photograph of James Lewis Cox, MD, in 1989. (Courtesy of Dr Cox.)
CTSnet and Thoracic Surgery Foundation for Research and Education. He has served as the editor in chief of Seminars in Thoracic and Cardiovascular Surgery (1996-2004), was founder and editor of Operative Techniques in Thoracic and Cardiovascular Surgery (1996-2004) and founder and editor of Pediatric Cardiac Surgery Annual (1997-2002), and has served on many other editorial boards. Dr Cox has served as a member on the National Institutes of Health Study Section Surgery and Bioengineering, owns 29 patents, and has approximately 350 publications. His numerous honors include North American Society of Pacing and Electrophysiology (now Heart Rhythm Society) Distinguished Scientist Award 1996, Ray C. Fish Award for Scientific Achievement, Texas Heart Institute, Honorary Member of the Russian Academy of Medical Sciences, American College of Surgeons John Gibbon Lecturer, and Society of Thoracic Surgery Bakken Distinguished Scientist Award.

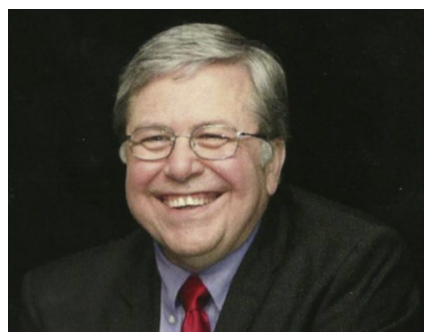

FIGURE 5. Photograph of Richard B. Schuessler, PhD. (Courtesy of Dr Schuessler.) 

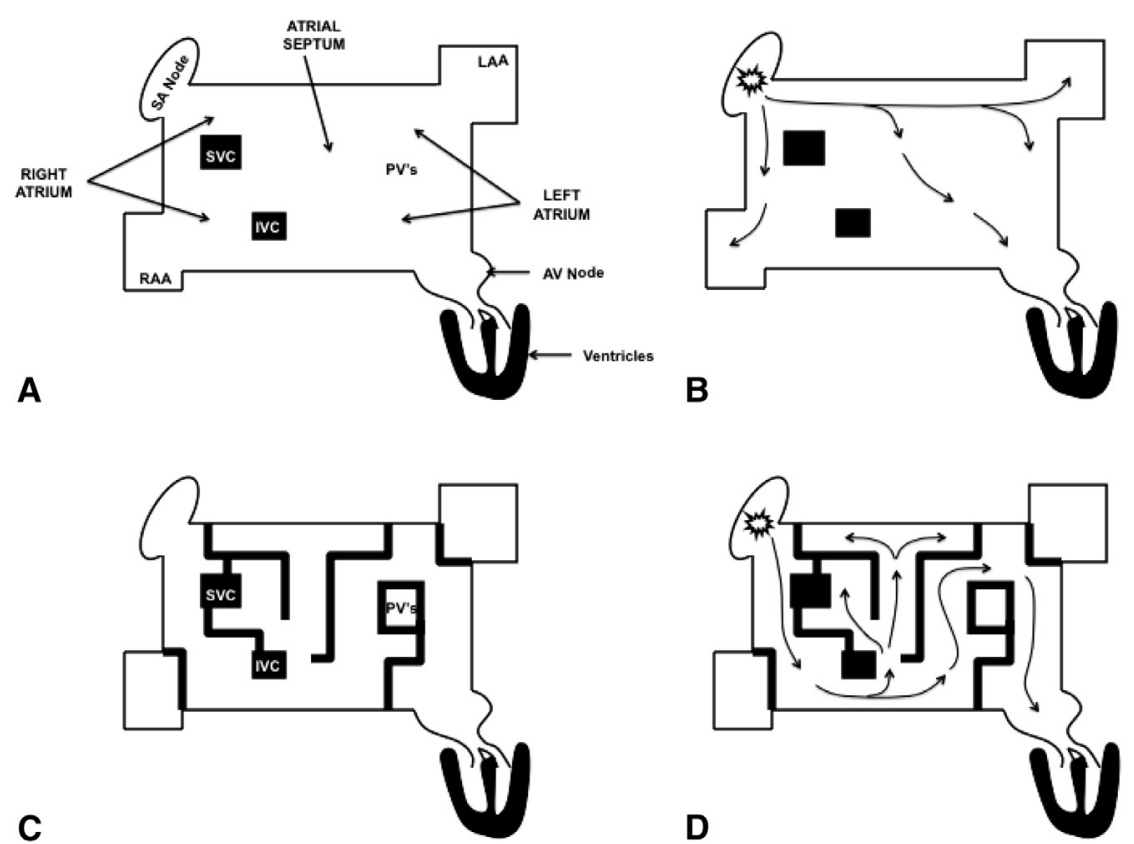

FIGURE 6. The concept of the maze procedure first envisioned in early 1987 aided by experimental maps of atrial fibrillation obtained by Richard B. Schuessler, $\mathrm{PhD}$, and John P. Boineau, MD. A, Two-dimensional representation of the anatomy of the atria with the right atrium harboring the orifices of the superior $(S V C)$ and inferior venae cavae $(I V C)$, as well as the right atrial appendage $(R A A)$. The left atrium has the pulmonary veins $(P V)$ and left atrial appendage $(L A A)$. The atrial septum divides the 2 with the sinoatrial $(S A)$ node in the top of the right atrium near the septum and the atrioventricular $(A V)$ node at the bottom of the septum connecting to the ventricles. B, Arrows depict the propagation of a normal sinus rhythm beat from its source (starburst) in the SA node to all of the atrial myocardium and then to its termination at the AV node. C, Heavy lines represent lines of conduction block created by lesions in the atria. By placing the lesions in the pattern of a maze, they can be placed close enough to prevent the development of macro-reentry anywhere in either atrium and still allow the sinus impulse to activate all of the atrial myocardium except the encircled pulmonary veins and excised atrial appendages (D). Reprinted with permission. ${ }^{4}$

Dr Cox served as chief executive officer (2000-2012) of the World Heart Foundation and still serves as the chair of the board of directors. He is presently the Emeritus Evarts A. Graham professor of surgery at Washington University.

\section{WORDS OF WISDOM}

Dr Cox's AATS presidential address entitled, "Changing Boundaries," was presented in San Diego, California, in
2001. Referring to thoracic surgeons, he spoke the following inspiring words:

We were born into an unforgiving social structure that uniformly condemned failure and rewarded only success. We were forged in the furnace of academic competition more mentally, psychologically, and physically brutal than any other group. We have spent our lives in the most stressful, serious, and complex

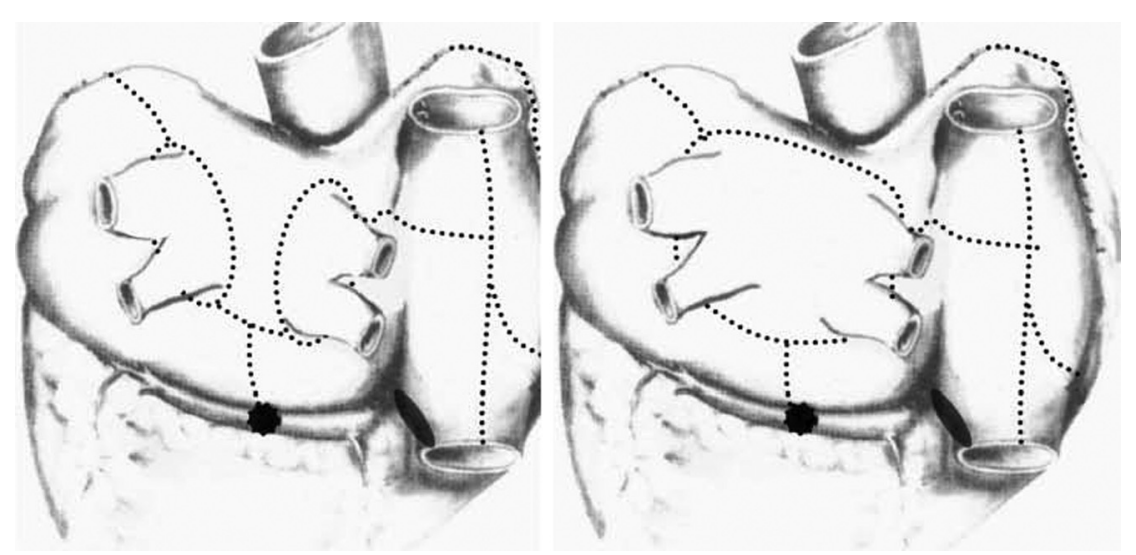

FIGURE 7. Cox-maze III procedure. Reprinted with permission. ${ }^{3}$ 
profession in the world, and we have thrived in it. People far more accomplished than we are respect us simply for what we do, and there are no boundaries to that respect. It is universal and extends across all social and geographic boundaries. No other group of people in the world can claim such a wonderful position in life or a more rewarding job! ... We have an obligation as uniquely talented individuals to change the boundaries of our thinking, the boundaries of our influence, and the boundaries of or efforts. ${ }^{5}$

Dr Cox presently resides in Denver, Colorado, and he continues to make important contributions to medicine and thoracic surgery, nationally and globally. His illustrious and exciting career, with important contributions to the understanding and treatment of atrial fibrillation, will help countless patients for years to come.

\section{AATS SCIENTIFIC ACHIEVEMENT AWARD}

The AATS presented the Scientific Achievement Award, one of the most prestigious honors that can be given by the AATS, to Dr Cox during the 95th Annual Meeting in
Seattle, Washington. The award was established to honor individuals who have achieved scientific contributions in the field of thoracic surgery worthy of the highest recognition. Dr Cox has been a true leader in advancing the science of cardiothoracic surgery and is the eleventh recipient of this prestigious awaed, joining such luminaries as Drs Kirklin, Shumway, Cooley, DeBakey, Carpentier, Buckberg, Wechsler, Weisel, de Leval, and Blackstone. It was with great pride that the AATS awarded the Scientific Achievement Award to James L. Cox for a distinguished investigative career that has profoundly benefited the specialty of cardiothoracic surgery.

\section{References}

1. Cox JL, Schuessler RB, D' Agostino HJ Jr, Stone CM, Chang BC, Cain ME, et al. The surgical treatment of atrial fibrillation: III. Development of a definitive surgical procedure. J Thorac Cardiovasc Surg. 1991;101:569-83.

2. Cox JL, McLaughlin WW, Flowers NC, Horan LG. The ischemic zone surrounding acute myocardial infarction: its morphology as detected by dehydrogenase staining. Am Heart J. 1968;76:650-9.

3. Cox JL. Cardiac surgery for arrhythmias. PACE. 2004;27:266-82.

4. Cox JL. The first maze procedure. J Thorac Cardiovasc Surg. 2011;141: 1093-7.

5. Cox JL. Presidential address: changing boundaries. J Thorac Cardiovasc Surg. 2001;122:413-8. 